\title{
Kinetic modeling for blood purification in critical care: this article is based on a study first reported in kidney and dialysis (in Japanese)
}

Michio Mineshima

\begin{abstract}
Background: In blood purification therapies for critical care, there are no guidelines for selecting modalities of the treatment or for determining the treatment schedule, treatment time, and operating conditions, such as dialysate flow rate $\left(Q_{D}\right)$ and filtration flow rate $\left(Q_{F}\right)$. In this paper, the solute removal characteristics of blood purification for critical care and the optimal operating conditions for individual patients are discussed from the viewpoint of kinetic modeling.
\end{abstract}

Method: An in vitro study using an aqueous solution involving several marker solutes was performed.

Results: From a result of the continuous hemodialysis (CHD) experiments, the $Q_{D}$ should be required at least twice the patient's blood flow rate $\left(Q_{B}\right)$ for sufficient removal of small molecular substances. CHD is of limited use for the removal of middle-sized molecules. During the continuous hemofiltration (CHF) experiments in the post-dilution mode, the maximum $Q_{F}$ value can be determined as about 1/4 of the $Q_{B}$ because of the existence of the formed elements. In summary of the continuous hemodiafiltration (CHDF) experiments, the $Q_{F}$ is about $1 / 4$ of $Q_{B}$ value and the $Q_{D}$ should be set up at least twice the $Q_{B}$ value.

The determination of adequate operating conditions for individual patients can be summarized from a kinetic modeling viewpoint:

1. Determination of the targeted solute according to the patient's state.

2. Determination of the generation rate of the targeted solute by collecting spent dialysate and/or filtrate.

3. Determination of the minimal requirement treatment dose from the actual and targeted solute concentration levels.

4. Choice of treatment modality and determination of the treatment time according to the clearance value.

Conclusions: Measurement of the removed amount of solute by collecting the spent dialysate and/or filtrate is recommended to maintain an adequate plasma level of the targeted solute of patients, who often have unstable states. The adequate operating conditions for each patient can be determined from a kinetic modeling viewpoint.

Keywords: Kinetic modeling, Compartment model, Adequate operating conditions

Correspondence: mmine@twmu.ac.jp

Department of Clinical Engineering, Tokyo Women's Medical University, 8-1,

Kawada-cho, Shinjuku-ku, Tokyo 162-8666, Japan 


\section{Background}

In blood purification therapies for critical care, there are no guidelines for selecting modalities, such as continuous hemodialysis (CHD), continuous hemofiltration (CHF), and continuous hemodiafiltration (CHDF), or for determining the treatment schedule, treatment time, and the operating conditions, such as the blood flow rate $\left(Q_{\mathrm{B}}\right)$, dialysate flow rate $\left(Q_{\mathrm{D}}\right)$, and filtration flow rate $\left(Q_{\mathrm{F}}\right)$, for individual patients. Instead, these conditions are determined according to the experience of the patient's doctor based on trial and error.

In this paper, the solute removal characteristics of blood purification for critical care and the optimal operating conditions for individual patients are discussed from the viewpoint of kinetic modeling.

\section{Solute removal characteristics of blood purification devices}

Blood purification therapy for critical care requires some specific conditions, compared with maintenance dialysis therapy for chronic kidney disease patients:

(1) A lower $Q_{B}$ is needed because the patient often has an unstable hemodynamic state and is unlikely to have an arteriovenous fistula (AVF) or arteriovenous graft (AVG).

(2) A longer treatment time is required because of the lower $Q_{\mathrm{B}}$.

(3) The patients are often actively bleeding.

Blood purification devices for critical care require the following characteristics:

(1) A compact size with a smaller priming volume $(P V)$

(2) A lower degradation for device performance

(3) A lower pressure drop on the blood side to avoid clotting in the device

Based on these requirements, a relatively small size of hollow fiber membrane device with a membrane surface area $(A)$ of $0.1-1.1 \mathrm{~m}^{2}$, a $P V$ of $12-87 \mathrm{~mL}$, and a slightly larger inner diameter of the hollow fiber $(220 \mu \mathrm{m})$ has been developed and used clinically.

To determine the solute removal characteristics of $\mathrm{CHD}, \mathrm{CHDF}$, and CHF, an in vitro study using an aqueous solution and a cellulose triacetate membrane filter, FB-50H, with an $A$ of $0.5 \mathrm{~m}^{2}$ (Nipro Corp, Osaka, Japan) was performed [1]. Reverse osmosis (RO) water including solutes was used for the blood side solution in all the experiments, and RO water was used for the dialysate in the HD and HDF experiments. Urea $(60 \mathrm{Da})$, creatinine $(113 \mathrm{Da})$, vitamin $\mathrm{B}_{12}$ $(1350 \mathrm{Da})$, and inulin $(5200 \mathrm{Da})$ were chosen as marker solutes in this study. Samples of the solute concentrations at the inlet and outlet of the blood side $\left(C_{\mathrm{BI}}\right.$ and $\left.C_{\mathrm{BO}}\right)$ and at the outlet side of the dialysate $\left(C_{\mathrm{DO}}\right)$ for $\mathrm{CHD}$ or $\mathrm{CHDF}$ and at the filtrate side $\left(C_{\mathrm{F}}\right)$ for $\mathrm{CHF}$ were obtained. All the experiments were performed using a multipurpose dialysis machine (ACH-07; Asahikasei Medical Co. Ltd., Tokyo, Japan).

The solute clearances were calculated using the following equations:

(1) Blood side clearance $\left(K_{\mathrm{B}}\right)$ for all experiments:

$$
K_{\mathrm{B}}=\frac{C_{\mathrm{BI}}-C_{\mathrm{BO}}}{C_{\mathrm{BI}}} Q_{\mathrm{BI}}
$$

(2) Dialysate side clearance $\left(K_{\mathrm{D}}\right)$ for the $\mathrm{CHD}$ and CHDF experiments:

$$
K_{\mathrm{D}}=\frac{C_{\mathrm{DO}}}{C_{\mathrm{BI}}} Q_{\mathrm{DO}}
$$

(3) Filtrate side clearance $\left(K_{\mathrm{F}}\right)$ for the CHF experiments:

$$
K_{\mathrm{F}}=\frac{C_{\mathrm{F}}}{C_{\mathrm{BI}}} Q_{\mathrm{F}}=S C \cdot Q_{\mathrm{F}}
$$

$S C$ is the sieving coefficient of the solute.

The left side of Fig. 1 shows the effects of $Q_{\mathrm{B}}$ on $K_{\mathrm{D}}$ in the CHD experiments under a $Q_{D}$ of $48.3 \mathrm{~mL} / \mathrm{min}$ with no filtration [1]. The $K_{\mathrm{D}}$ values for urea and creatinine increased with the $Q_{\mathrm{B}}$. The right side of Fig. 1 shows the effects of $Q_{\mathrm{D}}$ on $K_{\mathrm{B}}$ in the CHD experiments under a $Q_{\mathrm{B}}$ of $50.0 \mathrm{~mL} / \mathrm{min}$ with no filtration [1]. The $K_{\mathrm{B}}$ value increased steeply with $Q_{B}$ under a $Q_{D}<100 \mathrm{~mL} / \mathrm{min}$ and reached a plateau level at a $Q_{\mathrm{D}}$ of over $200 \mathrm{~mL} / \mathrm{min}$. Although a $Q_{D}$ of $500-1500 \mathrm{~mL} / \mathrm{h}$ was chosen from an economical viewpoint in a typical clinical treatment, $Q_{D}$ should be required at least twice the $Q_{\mathrm{B}}$ for the sake of obtaining sufficient $K_{\mathrm{B}}$ value. On the other hand, the vitamin $\mathrm{B}_{12}$ and inulin $K_{\mathrm{B}}$ values were less than half of the urea and creatinine $K_{\mathrm{B}}$ values. Thus, CHD is of limited use for the removal of such middle-sized molecules.

Figure 2 shows the effect of $Q_{\mathrm{F}}$ on $K_{\mathrm{F}}$ in the CHF experiments using a post-dilution mode under a $Q_{\mathrm{B}}$ of $50.0 \mathrm{~mL} / \mathrm{min}$ with no dialysate flow [1]. The $K_{\mathrm{F}}$ value increased proportionally with the $Q_{F}$. From Eq. 3, the slope of the proportional line indicates the 

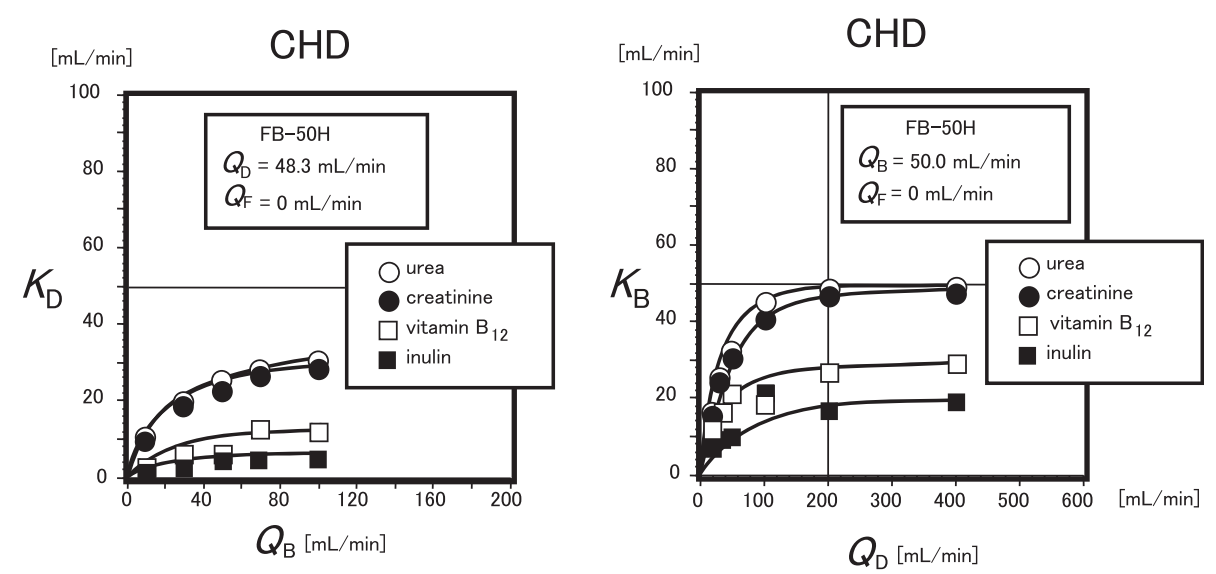

Fig. 1 Effects of blood flow rate $\left(Q_{B}\right)$ and dialysate flow rate $\left(Q_{D}\right)$ on solute clearance $(K)$ in the CHD experiments [1]

$S C$ value of the solute to the membrane device. Because the solute $S C$ value is almost unchanged for a device, the $K_{\mathrm{F}}$ value strongly depends on the $Q_{\mathrm{F}}$ (namely, the amount of replacement fluid, $V_{\mathrm{R}}$ ). In the post-dilution mode, the maximum $Q_{\mathrm{F}}$ value can be determined as about $1 / 4$ of the $Q_{\mathrm{B}}$ because of the existence of formed elements, such as erythrocytes.

Figure 3 shows the effects of $Q_{D}$ and $Q_{F}$ on $K_{\mathrm{B}}$ in the CHDF experiments using a post-dilution mode under a $Q_{\mathrm{B}}$ of $50.0 \mathrm{~mL} / \mathrm{min}$ [1]. As shown on the left

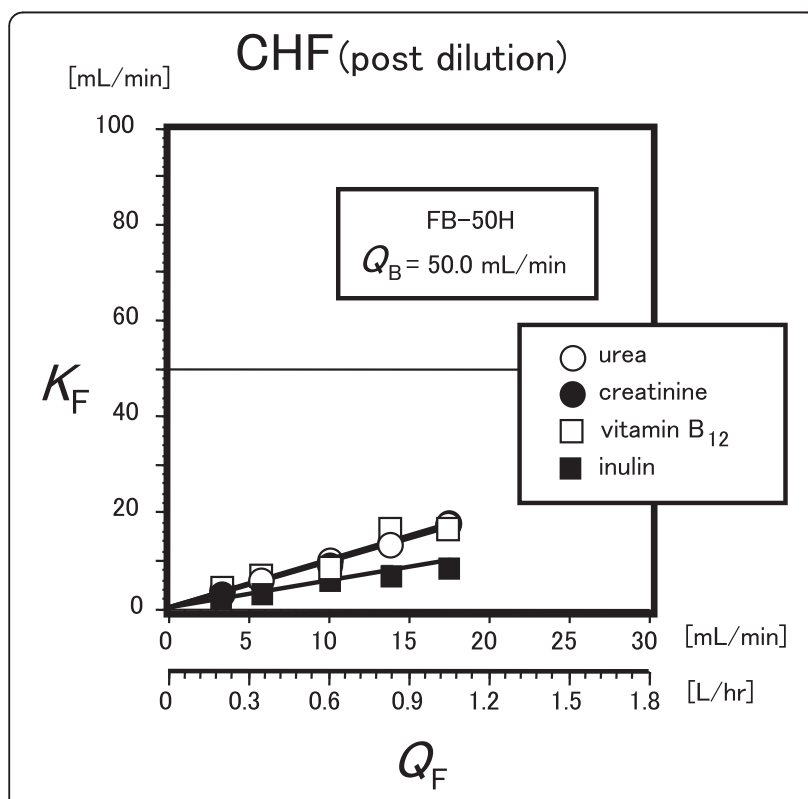

Fig. 2 Effects of filtration flow rate $\left(Q_{B}\right)$ on solute clearance $(K)$ in the CHF experiments [1] side of Fig. 3, the relationship between the $K_{\mathrm{B}}$ and $Q_{D}$ values was similar to that observed in the CHD experiments. The $K_{\mathrm{B}}$ values for vitamin $\mathrm{B}_{12}$ and inulin, however, slightly increased as a result of convective transport arising from a $Q_{F}$ of $10.4 \mathrm{~mL} / \mathrm{min}$. On the other hand, as shown on the right side of Fig. 3, a high efficiency of solute removal was obtained using both diffusive and convective transport in HDF using the post-dilution mode.

In summary, the $Q_{\mathrm{F}}$ is about $1 / 4$ of the $Q_{\mathrm{B}}$ value, and the $Q_{\mathrm{D}}$ should be set at least twice the $Q_{\mathrm{B}}$ value during CHDF treatment.

\section{Optimal operating conditions for blood purification therapies for critical care}

Determining the operating conditions for individual patients is very important for clinical treatment. An adequate $V_{\mathrm{R}}$ and $Q_{\mathrm{D}}$ can be determined from a kinetic modeling viewpoint. In this paper, the adequate parameters were determined using urea kinetic modeling [2].

If a 1-compartment model is used to describe urea transport during continuous renal replacement therapies (CRRT) such as CHD, CHF, and CHDF, the plasma solute concentration $(C)$ can be described as follows:

$$
\begin{aligned}
C & =\frac{G}{K_{\mathrm{av}}}=\frac{G T}{K t}=\left(\frac{G}{K}\right) \times\left(\frac{T}{t}\right) \\
& =\left(\frac{G T}{V}\right) \times\left(\frac{V}{K t}\right)
\end{aligned}
$$

where the symbols $G$ and $K_{\mathrm{av}}$ denote the urea generation rate and the time-averaged urea clearance, respectively. The $C$ can be defined as $G$ divided by $K_{\text {av }}$. After the $K t$ and $T$ in this equation, $C$ can be described as $G T / V$ divided by $K t / V$. The symbols $t$ and $T$ represent the 

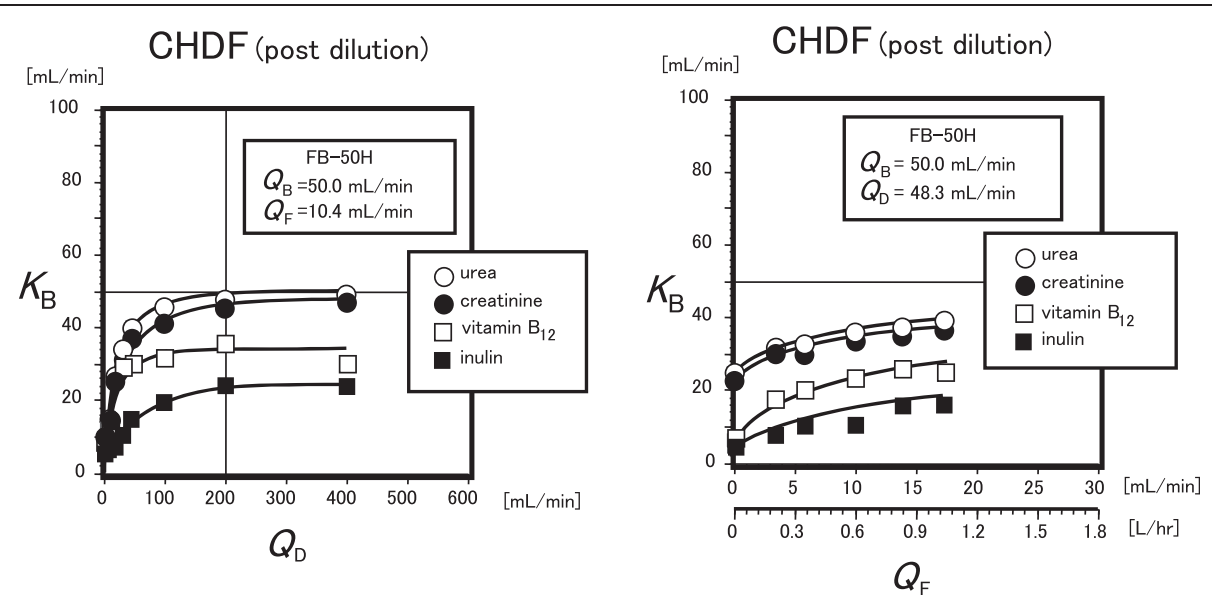

Fig. 3 Effects of dialysate flow rate $\left(Q_{D}\right)$ and filtration flow rate $\left(Q_{F}\right)$ on solute clearance $(K)$ in the CHDF experiments [1]

treatment time and the treatment cycle (for example, $24 \mathrm{~h})$. The $V$ denotes the urea distribution volume.

Material balance equations for urea can be applied as follows:

$$
\begin{aligned}
& M_{\mathrm{G}}=G T \\
& M_{\mathrm{R}}=K t \times C_{\mathrm{av}},
\end{aligned}
$$

where the symbols $M_{\mathrm{G}}$ and $M_{\mathrm{R}}$ denote the amount of urea generated and removed by CRRT, respectively. $C_{\mathrm{av}}$ means the time-averaged concentration of urea. The relations among $M_{\mathrm{G}}, M_{\mathrm{R}}$, and $C_{\mathrm{av}}$ can be described using the following 3 patterns:

(1) When $M_{\mathrm{G}}>M_{\mathrm{R}}$ for $\mathrm{T}$, the $C$ increases because the generation rate is superior to the removal rate.

(2) When $M_{\mathrm{G}}=M_{\mathrm{R}}$ for $\mathrm{T}$, the $C$ remains unchanged because the generation rate is equal to the removal rate.

(3) When $M_{\mathrm{G}}<M_{\mathrm{R}}$ for $\mathrm{T}$, the $C$ decreases because the removal rate is superior to the generation rate.

The change in the urea concentration, $\Delta C$, can be described as follows:

$$
\Delta C=\frac{M_{\mathrm{G}}-M_{\mathrm{R}}}{V}
$$

By substituting Eqs. 5 and 6 into Eq. 7, the following equations can be obtained:

$$
\begin{aligned}
& M_{\mathrm{G}}=M_{\mathrm{R}}+V \Delta C \\
& G=\left(M_{\mathrm{R}}+V \Delta C\right) / T
\end{aligned}
$$

As shown in Eqs. 8 and 9, the urea generation rate $G$ can be estimated by measuring the amount of urea removed by the CRRT treatment $M_{\mathrm{R}}$ and the change in the urea concentration $\Delta C$ for $\mathrm{T}$.

As an example, we supposed that a patient weighing $50 \mathrm{~kg}(\mathrm{BW})$ received a CRRT treatment and the BUN level of the patient increased from 80 to $100 \mathrm{mg} / \mathrm{dL}$ for $24 \mathrm{~h}$. If the $M_{\mathrm{R}}$ was obtained by collecting the spent dialysate and filtrate during the treatment and estimated as $5000 \mathrm{mg}$, the $G$ value of the patient can be calculated as follows using Eq. 9 and supposing $V$ (L) to be $60 \%$ of the BW (kg):

$$
\begin{aligned}
G & =\frac{5000+(50 \times 0.6) \times 10 \times(100-80)}{60 \times 24} \\
& =7.6 \mathrm{mg} / \mathrm{min}
\end{aligned}
$$

We can determine the optimal operating conditions of the CRRT treatment for the patient using urea kinetic modeling.

The amount of urea generated during $24 \mathrm{~h}$ can be estimated as follows:

$$
G T=7.6 \times 60 \times 24=11,000 \mathrm{mg}=11 \mathrm{~g}
$$

If the target of the BUN level is supposed to be $80 \mathrm{mg} / \mathrm{dL}$, the minimal requirement of the treatment dose can be calculated using Eqs. 5 and 6 as follows:

$$
K t=11,000 / 80=137.5 \mathrm{dL}=13.8 \mathrm{~L}
$$

From this estimation, the optimal operating conditions for several blood purification therapies can be determined as follows:

(1) CHF: The minimal amount of replacement fluid $\left(V_{\mathrm{R}}\right)$ is $14 \mathrm{~L}$.

(2) CHD: When the dialyzer clearance $(K)$ is assumed to be $30 \mathrm{~mL} / \mathrm{min}$, the treatment time can be calculated as follows: 
$13.8 \times 1000 / 30=458 \min =7.6 \mathrm{~h}$.

(3) CHDF: When the dialyzer clearance $(K)$ is assumed to be $40 \mathrm{~mL} / \mathrm{min}$, the treatment time can be calculated as follows:

$$
13.8 \times 1000 / 40=343 \mathrm{~min}=5.7 \mathrm{~h} .
$$

Although urea removal in CRRT therapies was mentioned above, CHDF and CHF (which are based on convective transport by filtration) are effective for the removal of relatively large molecules, such as some kinds of cytokines.

The determination of adequate operating conditions for individual patients who receive blood purification therapy for critical care can be summarized from a kinetic modeling viewpoint as follows:

1. Determination of the targeted solute according to the patient's state.

2. Determination of the generation rate of the targeted solute by collecting spent dialysate and/or filtrate.

3. Determination of the minimal requirement treatment dose from the actual and targeted solute concentration levels.

4. Choice of treatment modality and determination of the treatment time according to the clearance value K.

4-1 In CHF, the replacement volume $V_{\mathrm{R}}$ can be determined as $V_{\mathrm{R}}=K t$. The filtration flow rate $Q_{\mathrm{F}}$, which is identical to $K$, can be estimated as 15-30\% of the blood flow rate $Q_{\mathrm{B}}$. The treatment time $t$ can be determined by $K t / K$ $\left(=V_{\mathrm{R}} / Q_{\mathrm{F}}\right)$.

4-2 In CHD, the dialysate flow rate $Q_{D}$ should be set at least twice the $Q_{\mathrm{B}}$. The $t$ can be determined by $K t / K$.

4-3 In CHDF, the $Q_{F}$ and $Q_{D}$ should be shared according to the targeted solute. The $Q_{D}$ should be set at least twice the $Q_{\mathrm{B}}$. The $t$ can be determined by $K t / K$.

\section{Conclusions}

Measurement of the removed amount of solute by collecting the spent dialysate and/or filtrate is recommended to maintain an adequate plasma level of the targeted solute in critical care patients, who often have unstable states.

\section{Competing interest}

I declare that there are no conflicts of interest with any companies regarding this study.

Author's contributions

MM carried out this study and drafted the manuscript.
Received: 12 August 2015 Accepted: 12 October 2015

Published online: 16 December 2015

\section{References}

1. Hoshino T, Mineshima M, Shimizu M, Shibata M, Ishimori I, Kaneko I, et al. Experiments study for solute removal characteristics in continuous blood purification therapies (in Japanese). Intensive \& Critical Care Medicine. 1996; 8(Supple):S111-112.

2. Mineshima M. Kinetic modeling for blood purification in critical care (in Japanese). Kidney and Dialysis. 2005;58(5):561-5.

\section{Submit your next manuscript to BioMed Central and take full advantage of:}

- Convenient online submission

- Thorough peer review

- No space constraints or color figure charges

- Immediate publication on acceptance

- Inclusion in PubMed, CAS, Scopus and Google Scholar

- Research which is freely available for redistribution 